\title{
DEVELOPMENT OF WAVE OVERTOPPING MODEL INCORPORATING WATER OVERFLOW FOR VERTICAL WALLS
}

\author{
Yoii Tanaka, ECOH Corporation, y-tanaka@ecoh.co.jp \\ Katsuyuki Suzuyama, ECOH Corporation, suzuyama@ecoh.co.jp \\ Naoto Higuchi, ECOH Corporation, higuchi@ecoh.co.jp \\ Hidenori Shibaki, ECOH Corporation, shibaki@ecoh.co.jp
}

\section{INTRODUCTION}

In a situation where water overflow occurs on the seawalls due to a storm surge, generally it is high waves that cause wave overtopping. However, it is common that overflow and overtopping are modeled as separate phenomena, in a situation where both phenomena occur at the same time, the amount of water exceeding the seawalls may not be evaluated correctly. The purpose of this research is to develop a new wave overtopping model including the water overflow for vertical seawalls.

The new overtopping model improved the overtopping model of Goda (Goda, 2008: Goda08 model). Goda08 model was developed to adapt for various seawall forms. Goda (2008) insisted it was more accurate than EurOtop model. Nonetheless, Goda08 model has a problem of overestimation in shallow area. Therefore, we tuned the parameters again.

It is difficult to reproduce the situation where the overtopping and overflow occur at the same time in a hydraulic experiment. Consequently, CADMAS-SURF which is based on the 2-dimensional non-compressive fluid using the VOF method was used as an experimental data provider for comparative verification of the model.

\section{IMPROVEMENT OF WAVE OVERTOPPING MODEL}

Goda08 wave overtopping model was compared with the wave overtopping diagram of Goda et al. (1975) (Goda75 model), laboratory data (Goda et al., 1975) and numerical observation of CADMAS-SURF (Figure 1). where, $H_{0}^{\prime}$ (= $K_{d} \cdot K_{r} \cdot H_{0}$ ) is equivalent deepwater wave height, $K_{d}$ is diffraction coefficient, $K_{r}$ is refraction coefficient, $H_{0}$ is deepwater wave height, $h$ is depth at the structure toe, $R_{c}$ is crest freeboard from still-water level, $L_{0}$ is deepwater wave length. $H_{S}$ (significant wave height at the structure toe) was changed to $H_{0}^{\prime}$ by Goda (1975). Goda75 model was underestimated in large relative depths $\left(h / H_{0}^{\prime}>3\right)$. Goda08 model solved the problem of being underestimated at a large relative depth. However, the behavior of Goda08 model was unstable in small relative depths $\left(h / H_{0}^{\prime}<0.2\right)$.

To solve these problems, we improved Goda08 model (Equations (1) - (11)). The proposed model is consistent with the Goda08 model in large relative depths, and close the experimental results in small relative depth (Figure 1). Figure 2 shows a comparison between the laboratory data (Goda et al., 1975), proposed model, and Goda08 model. We confirmed that the proposed model has an accuracy equal to or higher than that of Goda08 model. Figure 3 shows the results of comparing the wave overtopping models (proposed model, Goda08 model, and EurOtop model (Van del Meer and Bruce, 2014)) with experimental data from the CLASH database for vertical seawall. The proposed model agreed well with various experimental data.

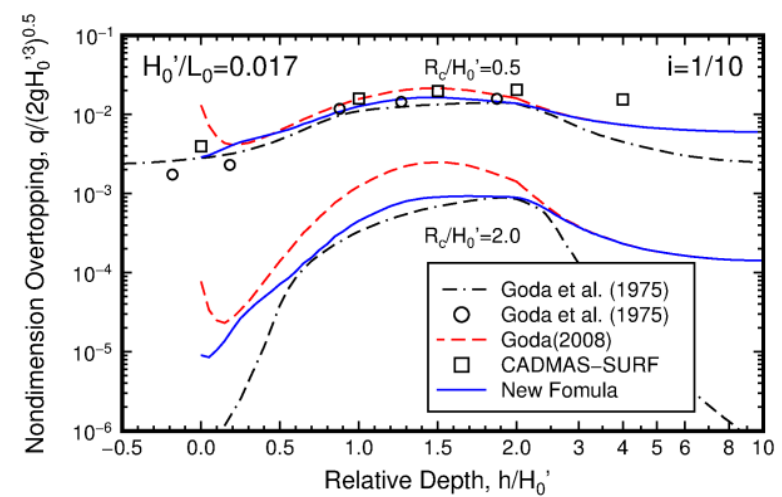

Figure 1 - Comparison of wave overtopping diagram (Goda et al., 1975), Goda08 model, the new formula, laboratory data (Goda et al., 1975) and numerical experiment (CADMAS-SURF).

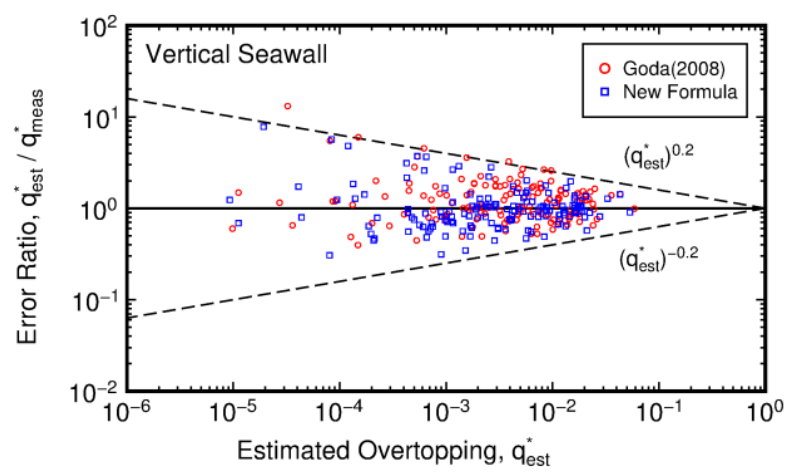

Figure 2 - Prediction error of Goda (2008) model and the new formula.

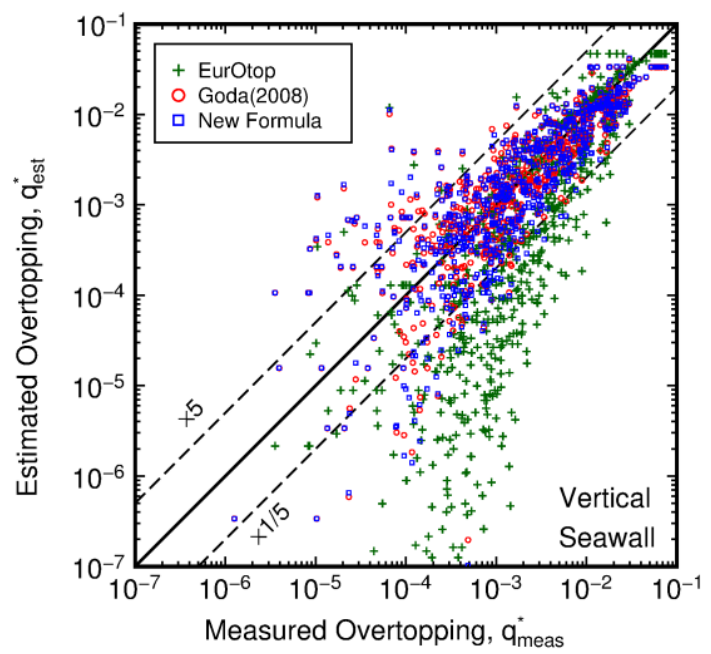

Figure 3 - Validation of EurOtop model (Van del Meer and Bruce, 2014), Goda (2008) model and the new formula by using CLASH datasets for vertical walls. 


$$
\begin{gathered}
q_{t}^{*}=\frac{q_{t}}{\sqrt{g H_{s}^{3}}}=\exp \left(-A-B \frac{R_{c}}{H_{s}}\right) \\
A=A_{0} \tanh A_{1}+A_{2} \\
B=B_{0} \tanh B_{1}+B_{2} \\
A_{0}=\frac{3.4-\min (15.0 \tan \theta+0.22,3)}{2}
\end{gathered}
$$

$A_{1}=\max (18.0 \tan \theta+0.60,1.0) x-11.7 \tan \theta-0.51$

$$
\begin{gathered}
A_{2}=\frac{3.4+\min (15.0 \tan \theta+0.22,3)}{2} \\
B_{0}=2.3
\end{gathered}
$$

$$
B_{1}=(1.50 \tan \theta+0.45) \cdot x+0.965 \exp (-5.62 \tan \theta)
$$

$B_{2}=\frac{2.25 \tan \theta+0.225}{\sqrt{2 \pi} w x}$

$$
\begin{gathered}
\cdot \exp \left[-\frac{\{\ln (x)-0.577+4.09 \tan \theta\}^{2}}{2 w^{2}}\right] \\
w=1.50 \tan \theta+0.11 \\
x=h / H_{s}
\end{gathered}
$$

where, $q_{t}$ is wave overtopping rate, $q_{t}^{*}$ is dimension less wave overtopping rate, $\theta$ is slope of the foreshore.

\section{DEVEROPMENT OF WAVE OVERTOPPING MODEL INCORPORATING WATER OVERFLOW}

We carried out numerical experiments which occurred overflow and overtopping using CADMAS-SURF. The new overtopping and overflow model was developed with these experiments. The basic equation of the new model is written as:

$$
\begin{gathered}
q= \begin{cases}q_{t} & \left(R_{c} \geq 0\right) \\
q_{f}+q_{t, \text { max }} \cdot \exp \left(-C \frac{R_{c}}{H_{s, t o e}}\right) & \left(R_{c}<0\right)\end{cases} \\
q_{t}=q_{t}^{*} \sqrt{g H_{s, t o e}^{3}} \quad\left(R_{c} \geq 0\right) \\
q_{f}=0.35 \sqrt{2 g\left(-R_{c}\right)^{3}} \quad\left(R_{c}<0\right)
\end{gathered}
$$

where $q_{f}$ is overflow rate, $q_{t, \max }\left(=q_{t}\left(R_{c}=0\right)\right)$ is wave overtopping rate for zero freeboard, $C$ is decrease coefficient of overtopping rate.

Figure 4 shows the relative water level versus overtopping and overflow discharge rate. In the area of $-R_{c} / H_{0}^{\prime} \leq 0$, only overtopping occurs. And in the area of $-R_{c} / H_{0}^{\prime}>0$, overtopping and overflow occur at the same time. The new formula agreed closely with the experimental data produced by CADMAS-SURF.

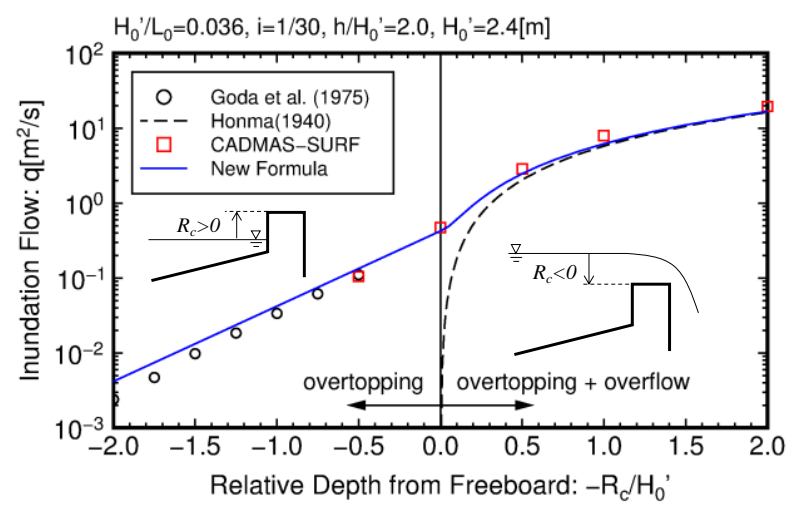

Figure 4 - Relative water depth from freeboard versus inundation flow (overtopping and overflow discharge)

\section{CONCLUSION}

This study improved the overtopping model based on Goda (2008) model and developed the model integrating wave overtopping and overflow. The high accuracy of the proposed model was confirmed by comparing with the wave overtopping diagram (Goda et al., 1975) and CLASH datasets.

\section{REFERENCES}

EA (NK), ENW (NL), KFKI (DE), EurOtop Wave Overtopping of Sea Defences and Related Structures: Assessment Manual, 185p. 2007.

Goda, Y., Deformation of Irregular Waves due to DepthControlled Wave Breaking, Report on the Port and Harbour Research Institute, Vol. 14, No. 3, pp. 59-106, 1975.

Goda, Y., Y. Kishira, Y. Kamiyama, Laboratory Investigation on the Overtopping Rate of Seawalls by Irregular Waves, Report on the Port and Harbour Research Institute, Vol. 14, No. 4, pp. 3-44, 1975.

Goda, Y., Derivation of Unified Wave Overtopping Formulas for Seawalls with Smooth, Impermeable Surfaces Based on Selected CLASH Datasets. Coastal Engineering, Vol. 56, No. 4, pp. 385-399, 2009. Van del Meer, Tom Bruce, New Physical Insights and Design Formulas on Wave Overtopping at Sloping and Vertical Structures, J. Waterway, Port, Coast., and Ocean Eng., Vol.140, Issue 6, p.04014025, 2014. 